\title{
El mito de Inanna y Šukaletuda: violencia sexual en Sumer
}

Estefanía Bernabé-Sánchez*

Resumen: El siguiente articulo trata el tema de la violencia sexual a través del mito sumerio de Inanna y Šukaletuda,donde la diosa Inanna es violentada por el mal jardinero Šukaletuda, estableciendo un paralelismo entre el crimen sexual cometido contra la diosa y aquellos que están siendo hoy moneda común en los conflictos armados de Oriente Medio, especialmente en Siria. El mito habla también de la funesta disociación entre los conceptos de ser y naturaleza, en la que entendemos está inserta intrínsecamente la condición femenina, representada por la diosa Inanna.

Palavras clave: Mitología. Inanna. Šukaletuda. Sumeria. Estupro.

\section{Introducción}

Según los informes del proyecto Women under Siege, dirigido por la periodista estadounidense Lauren Wolf ${ }^{1}$ a través del Women's Media Center, sabemos que las violaciones se han convertido en una de las más poderosas armas de guerra, elemento de represión y castigo más utilizado contra las mujeres, especialmente en los conflictos armados de África y Oriente Medio.

En Siria, por ejemplo, tanto el Ejército como la milicia o los grupos paramilitares (shabihah) han sido acusados de llevar a cabo violaciones masivas en centros de detención y casas particulares, muchas veces ante la presencia de las propias familias de las víctimas. La psiquiatra siria Yassar Kanawati, que lleva tiempo

"Doutora em Letras e professora da Pontificia Universidad Católica del Perú. E-mail: e.bernabe1976@gmail.com. 
recabando información sobre violencia sexual entre los refugiados sirios desplazados a Jordania y el Líbano, es tajante al afirmar que, en Siria, "rape has been reportedly used widely as a tool of control, intimidation and humiliation throughout the conflict" [el estupro se ha utilizado sistemáticamente como herramienta de control, intimidación y humillación durante el conflicto]. Kanawati hace especial hincapié en el concepto de trauma asociado a estas violaciones sistemáticas y llega a referirse, incluso, a cientos de niñas sirias como "la generación perdida", por la inestabilidad emocional que supone enfrentar, no solo una guerra y sus consecuencias a todos los niveles, sino también una agresión sexual de estas características. Para intentar que el máximo número de mujeres pueda superarlo, por cierto, la SAMS (Syrian American Medical Society Foundation, dirigada por el Dr. Amjad Rass) ha puesto en marcha varios programas en algunas de las ciudades más afectadas por el conflicto bélico, como Damasco, Idlib, Quneitra, Homs o Aleppo.

En tal contexto, parece más que pertinente echar un vistazo a las raíces socioculturales de la zona, a los albores de la civilización mesopotámica, para profundizar en uno de los primeros casos de violencia sexual contra la mujer de los que tenemos constancia documentada. Aunque no hay guerra en la narración que nos ocupa, tal como hoy la entendemos, sí se comete abuso y crimen, sí hay un acto inicuo que llama la atención hasta el punto de ser colocado por escrito. En el mito, sin embargo, y al contrario que en la Siria actual, también hay espacio para una impugnación de la víctima, en este caso la diosa Inanna, como veremos. Nos referimos al mito de Inanna y ̌̌ukaletuda, conservado en dos tablillas sumerias con alrededor de trescientos versos en total: 
La Señora de grandes Poderes

Digna de sentarse en el Estrado

Inanna de grandes Poderes [...]

Quiso, un día descender hasta aquí abajo ¡La santa Inanna quiso descender a la tierra!

¡Para separar a los mezquinos y los justos, sondear los espíritus dentro del país, (para) separar lo verdadero de lo falso, quiso ella descender hasta aquí abajo!

¡Cuánto se te debe alli abajo! ¿Cuánto se habla todavía de ti! ${ }^{4}$

\section{Historia del mito}

En 1949, Samuel Noah Kramer publicaba una traducción inédita de dos tablillas y algunos fragmentos fechados en el primer tercio del II milenio, en los que se hablaba explícitamente de una agresión sexual cometida contra Inanna, la gran "Señora del cielo" del panteón sumerio, y de las terribles represalias de ésta sobre la tierra en busca de su agresor ${ }^{5}$. Ya a mediados de los años 90, Konrad Volk, profesor de la Universidad de Tübingen, fue el primero en llevar a cabo una edición crítica del texto pleno con su traducción, siendo la incursión más completa en el mismo hasta el momento (VOLK, 1995).

Las primeras estrofas, de las que arriba hemos colocado un extracto, conforman una especie de introducción hímnica al poema (versos 1-41), con loas a la diosa. En ellas, además de entrever ya la maravillosa cadencia de la poesía mesopotámica y su belleza rítmica, se nos informa del apremiante deseo de Inanna: bajar a la tierra para llevar a cabo la primordial disociación deífica: separar el bien del mal, los espíritus mezquinos de los puros, la verdad de la mentira. Con ello, la diosa espera tomar contacto con el mundo de los mortales y medir su propia autoridad, conocimiento que todavía no tiene. Este viaje es visto por algunos estudiosos como 
una especie de desplazamiento astral que identificaría a Inanna con el planeta Venus y sus movimientos celestes (vide COOLEY, 2008).

A continuación se presenta al dios Enki, padre de Inanna, dando instrucciones al personaje del Cuervo (versos 42-88) para que realice "una labor de Hombre", esto es, que lance al aire paladas de tierra y prepare el terreno baldío para poder sembrar. Enki, no lo olvidemos, es también el gran dios sumerio del agua. De este esfuerzo colectivo entre el mundo divino (representado por el dios) y el natural (representado por el pájaro) nace otro símbolo mesopotámico por antonomasia, el árbol, en este caso, una palmera "progenitora de los cursos de agua", un "árbol inmortal” de cuyos cuidados va a encargarse un jardinero llamado Šukaletuda:

Pues este era el nombre del (jardinero?) [deshecho en lágri]mas y pálido de tristeza: (Pues) él había regado los [arriates], $Y$ preparado hoyos con agua junto a los [bancales]: Pero allí no crecía nada ¿Por qué? ¡Todo había sido arruinado por ese viento tempestuoso! ¿[Que a la cara] de Šukaletuda Había lanzado el [polvo del s]uelo Hasta inflamarle [los ojos] Y ̌́ukaletuda se vio obligado [a limpiar] sin descanso (el jardín!)

Tanto Bottéro y Kramer (2004, p. 281) como otros estudiosos posteriores ven en el Cuervo el germen mágico del jardinero Sukaletuda. Sin embargo, cuesta creer que este animal de alturas que ayuda a Enki a crear el jardín perfecto, y tan concienzudamente, se convierta en el nefasto jardinero del poema, el que no sabe descifrar el mundo natural, no lo entiende, y que además lo profana con un acto atroz cometido contra la diosa de la abundancia y la fertilidad, Inanna, como veremos. Estos últimos versos que reproducimos arriba ponen de manifiesto la dificultad de Šukaletuda para mantener este jardín divinal, por lo que defendemos que el Cuervo y el jardinero sean dos personajes diferenciados, con papeles disímiles 
en la historia. La incomprensión de la naturaleza por parte de Sukaletuda es, en el fondo, la incomprensión del mundo femenino representado por la diosa, y de la condición femenina como un todo mayor. Esta ignorancia, este desconocimiento de lo femenino y su desconsideración, entonces, se nos muestran como actos punibles para la sociedad sumeria, y serán debidamente castigados.

Recordemos también que el jardín es, tanto para la cultura mesopotámica como para su radio de acción posterior, la perfección sistémica, un lugar crucial para entender la cosmovisión de las sociedades desérticas, donde se alcanza el nivel más alto de bienestar posible. Pensemos por ejemplo en el mítico Dilmún sumerio $^{6}$, en Babilonia y la maravilla de sus jardines colgantes ${ }^{7} \mathrm{o}$ en los jardines de los palacios persas, imágenes que se fusionan con el Edén paradisíaco.

Por lo tanto, el hecho de que este jardinero no consiga mantener vivo y verde este vergel instaurado por Enki es altamente significativo. Y lo es porque Sukaletuda no sabe interpretar los signos naturales que lo rodean en la tierra, como hemos dicho, por lo que debe recurrir a la divinidad que lo protege y dirigir sus ruegos al cielo. Este vínculo roto entre hombre y entorno natural - mundo femenino tampoco debe ser pasado por alto, y anticipa la actitud funesta del protagonista. Por suerte para él, es inspirado por el cielo a plantar una hilera de álamos que le ayuden a dirigir los vientos:

Alzando, entonces, la mirada, Contempló las estrellas de Oriente [...] Tomó en cuenta las estrellas de Occidente; Tuvo cuidado de [los espíritus que, aislados, merodean];

Estudió los signos de los [demonios

Que vagabundean solitarios] Aprendió a aplicar los Poderes, Meditando acerca de los destinos asignados por los dioses. Después [...] plantó una hilera (?) de árboles frondosos Álamos muy frondosos, Cuya sombra, tanto por la mañana, Como al mediodía y por la tarde, nunca llegaría a faltar. 
Precisamente será esta sombra, primera victoria del jardinero sobre el espacio, la que atrae a la diosa quien, exhausta de su viaje por cielo y tierra, procura un lugar donde poder retirarse a descansar. Acechante, Šukaletuda, el jardinero para quien la naturaleza es ininteligible, ve a esta bellísima mujer entrar en su jardín y acomodarse.

Inanna, delante de su sexo y a modo de taparrabos, Se había atado los Siete Poderes

Sabemos por otros fragmentos mitológicos que Inanna había robado a su padre, el dios Enki, uno de los dones más preciados de la civilización mesopotámica, los meh, esto es, las reglas del juego de la civilización, o lo que podía ser un estadio anterior a un conjunto reglado de leyes, y los había llevado de Eridu a Uruk. Los meh eran una poderosísima herramienta de cohesión social, decretados por la divinidad (y, por tanto, inmutables) que garantizaban la comunicación y el entendimiento entre dioses y hombres. Se trataba de una serie de costumbres, comportamientos sociales, avances técnicos, prácticas religiosas y estatutos que legitimaban el equilibrio entre el macro y el microcosmos, y regían el funcionamiento ideal de la civilización. Inanna, desnuda, se ata los meh o Siete Poderes a la cintura, y estos caen "sobre su augusto sexo".

\title{
Consumación de la violación e ira de la diosa
}

\author{
[Luego ella se durmió] \\ Pero Šukaletuda separa el paño protector, \\ la besa y la penetra, \\ Tras lo cual volvió al extremo del jardín
}

Aquí, entre los versos 120 y 125 es donde tiene lugar el silencioso estupro de la diosa, recordemos que por parte de un mortal, un jardinero que no consigue mantener vivo y verde su jardín, que no sabe interpretar el mundo natural-femenino, y que consuma este 
acto de manera taciturna, amparado por las sombras de la noche. El jardinero besa y penetra a la diosa, que descansa bajo un árbol. Al alba, Inanna despierta y es consciente de lo ocurrido,

Inanna se mira con detalle, Y comprende que había sido ultrajada ¿Qué catástrofe provocó, la santa Inanna, Por culpa del ultraje a su sexo! [...] Llenó de sangre todos los pozos (del país), Introdujo sangre En todos los depósitos de los jardines! [...] Y ella decía: "Deseo encontrar a mi agresor Donde quiera que esté"

La ira de Inanna al saberse afrentada no tiene fin. La diosa decide organizar su particular venganza contra la tierra que cobija a su agresor, con la esperanza de que se entregue, o lo entreguen sus conciudadanos. La primera plaga que la diosa envía a la tierra convierte toda el agua en sangre. Este acto tendrá enorme repercusión posterior, especialmente en la escatología y ritualística hebrea, así como en la literatura profética. Esta sangre del poema, como ya apuntó Kramer, puede tener que ver con el agravio físico a la diosa, su desfloración, que provoca un castigo con el mismo elemento como protagonista.

A pesar de toda su furia, Inanna no consigue hallar al culpable. Šukaletuda está escondido en la casa de su padre, a quien relata todo lo ocurrido. Su padre le aconseja perderse entre la multitud de la ciudad,

Hijo mío, permanece cerca de tus hermanos, Los habitantes de la ciudad, Mézclate decididamente con tus semejantes [...] Y [la Mujer nunc]a lo pudo encontrar!

Este dato es muy significativo, pues refrenda el carácter cohesionador del concepto de ciudad, nacido en los albores de la 
civilización mesopotámica como proyecto de unificación económica y socio-política. El pictograma cuneiforme sumerio para ciudad es Y, URU o IRI ${ }^{8}$, presente en las denominaciones de los primeros asentamientos humanos, las primeras ciudades, como Eridu, Ur o Uruk (todas contienen los fonemas mencionados), fundadas entre el 3.500 y el 3.000 a.C. en lo que hoy es el (despedazado) territorio de Irak ${ }^{9}$. Esta especie de escamoteo del mortal entre la masa de sus semejantes enfurece sobremanera a Inanna, que decide enviar una segunda plaga, también en la forma de un castigo colectivo:

$Y$ he aquí la catástrofe (que) [la Mujer] provoca [por segunda vez], Por culpa del ultraje a su sexo, He aquí lo que Inanna provoca: Montándose sobre las nubes [...] Desencadena los malos vientos, $Y$ hace girar los ciclones. Tras ella se alzaban los huracanes (?) Y los tornados de polvo [...] $Y$ ella (decía): "Deseo encontrar a mi agresor, Donde quiera que esté"

De nuevo Šukaletuda acude a buscar el consejo de su padre, quien vuelve a sugerirle que se mezcle anónimamente entre las gentes de la ciudad. Llega entonces la tercera plaga de Inanna, la más oscura de desentrañar, pues el texto dice simplemente que "corta los caminos", sin darnos más explicaciones, en una estrofa muy fragmentaria. Se entiende que bloquea todos los caminos, entorpeciendo el libre movimiento de la población. Una vez más, tenemos a Šukaletuda en la casa paterna, y de nuevo el mismo consejo de diluirse entre sus semejantes (los cabezas negras, según el texto, color de las cabelleras humanas que los dioses veían desde lo alto). Asistimos entonces a la desesperación de la diosa: 
El sol se alza, el alba aparece Y la Mujer, mirándose con detenimiento, Vuelve a pensar en el ultraje sufrido: ¡Pobre de mí! (decía) ¿Quién me ayudará? ¡Pobre de mí! ¿Quién me socorrerá? ¡Él, realmente, tiene que estar en casa de su padre, En el palacio de Enki!

Se nos revela aquí el nombre del padre de Šukaletuda, que resulta ser el mismo dios Enki; tal vez estemos ante una apropiación del título de progenitor que es, en realidad, un empleador, un mentor. Sea como fuere, Inanna ruega a Enki que le entregue a su agresor, amenazándole con abandonar su templo de Uruk. Su afán coercitivo surte efecto, y Enki le entrega al jardinero.

\section{Castigo y clemencia}

La [santa] Inanna, entonces, se llevó consigo a Šukaletuda Desde el apsû de Éridu. ¡Se atraviesa en el firmamento Como un arco iris [...] se acerca, [...] se acerca más [...] $Y$ Šukaletuda se hace cada vez más pequeño

Lamentablemente, el final es el pedazo más mutilado del texto, y donde más lagunas tenemos. Sabemos que la diosa "golpea” (verso 284) a su agresor, es decir, que finalmente le infringe el castigo físico que ya habíamos atisbado en el último verso arriba señalado, determinando su destino, cuando él se iba empequeñeciendo mientras Inanna se iba convirtiendo en un magnífico arco iris. Quizás signifique esto la pena de muerte para Šukaletuda, un criminal en toda regla para la sociedad mesopotámica (no debemos descartarlo), tal como recoge la Ley 130 del Código de Hammurabi, que castiga la violación con la muerte. 
Con todo, finalmente, la magnánima Inanna abre una puerta a la clemencia y ofrece a Šukaletuda la opción de la inmortalidad. Pensemos que, mientras la venganza obedece a la razón ciega, Inanna opta por otorgar una especie de perdón a su agresor en la forma de una memoria eterna para su afrenta, que ilustre a las generaciones venideras sobre el agravio sufrido por ella:

\author{
Y la [santa] Inanna dice a Šukaletuda: \\ ¡Ś́, incluso cuando haya hecho de ti [...] \\ Tu nombre nunca llegará a caer en el olvido, \\ Pervivirá en los cánticos - y serán cánticos suaves \\ En los palacios de los reyes \\ Los cantarán los jóvenes [trovadores (?)] \\ $Y$ los past[ores] los canturrearán \\ Mientras baten el odre de leche
}

Termina el poema con una afirmación doxológica que merece la pena suscribirse por la compasión mostrada por la diosa,

gloria a ti, Inanna.

Sin embargo, y cerrando el círculo con el que empezábamos este artículo, hemos de reconocer que, lamentablemente, los mortales herederos de la diosa sumeria siguen inmersos en la ceguera de la violencia donde el estupro es moneda común. La generosidad y el castigo ejemplar de Inanna no han dado sus frutos -seamos optimistas con el adverbio- todavía. Que las generaciones futuras puedan aprender a leer entre las líneas de la antigüedad es el desafío nuestro de cada día, y que las leyes humanitarias básicas, así como los derechos humanos fundamentales, se cumplan de una vez por todas, en cualquier parte del mundo.

Esta, como vemos, es una lucha multisecular de dioses y diosas, de mujeres y hombres de bien, pero no debe darse nunca por perdida. 


\section{O MITO DE INANNA E ŠUKALETUDA: VIOLÊNCIA SEXUAL NA SUMÉRIA}

Resumo: O seguinte artigo trata o tema da violência sexual através do mito sumério de Inanna e Šukaletuda, no qual a deusa Inanna é estuprada pelo mau jardineiro Šukaletuda, estabelecendo um paralelismo entre o crime sexual cometido contra a deusa e aqueles que estão sendo hoje moeda comum nos conflitos armados do Oriente Médio, especialmente na Síria. O mito também fala da funesta dissociação entre os conceitos de ser e natureza, na qual entendemos está inserida intrinsecamente a condição feminina, representada pela deusa Inanna. Palavras-chave: Mitologia. Inanna. Šukaletuda. Suméria. Estupro.

\section{THE MYTH OF INANNA AND ŠUKALETUDA: SEXUAL VIOLENCE IN SUMER}

Abstract: The following article analyzes a case of sexual violence through a Sumerian myth known as Inanna and Šukaletuda, where Sumerian goddess Inanna is raped by the bad gardener, Šukaletuda, establishing a parallelism between the sexual crime committed against the goddess, and those that are being standard practice in the various Middle East armed conflicts, especially in Syria. The myth also explores the ill-fated dissociation between the concepts of being and nature, in which we understand feminine condition is intrinsically added, represented by goddess Inanna.

Keywords: Mithology. Inanna. Šukaletuda. Sumer. Rape.

\section{Notas}

${ }^{1}$ Disponible en: 〈www.womensmediacenter.com/women-under-siege/>. Acceso en: 1 marzo 2018.

${ }^{2} \mathrm{Y}$ no solo contra la mujer, también contra el hombre. Puede leerse una interesante entrevista realizada a Kanawati aquí: 〈https://www.theatlantic.com/ international/archive/2013/04/syria-has-a-massive-rape-crisis/274583/>. Acceso en: 1 marzo 2018.

${ }^{3}$ KANAWATI, Y. Saving the lost generation of Syria. Mental Health \& Human Resilience International Journal, v. 1, issue 2, nov. 2017. Disponible en: <https:// medwinpublishers.com/MHRIJ/MHRIJ16000111.pdf>. Acceso en: 1 marzo 2018. 
${ }^{4}$ Puede leerse la transcripción completa del mito y su traducción al inglés en el corpus de textos sumerios de la Universidad de Oxford en The Electronic Text Corpus of Sumerian Literature. Disponible en: 〈http://etcsl.orinst.ox.ac.uk/>. (Su primer verso es /in-nin $\backslash$ me gal-gal-la /barag $\mid$ ge4 he2-du7). Nosotros confrontamos ésta con el texto propuesto por Francisco Javier González, el traductor de Cuando los dioses hacían de hombres: Mitología Mesopotámica, de Jean Bottéro y Samuel Noah Kramer.

${ }^{5}$ KRAMER, Samuel Noah. A Blood-plague Motif in Sumerian Mythology. Archiv Orientální, Praha 8, v. 17, n. 1, p. 399-415, 1945.

${ }^{6}$ Vide CRAWFORD, Harriet E. W. Dilmun and its Gulf neighbours. Cambridge: Cambridge University Press, 1998.

${ }^{7}$ Para mayor información acerca del concepto pueden consultarse los estudios de DALLEY, S. The Mystery of the Hanging Garden of Babylon: An Elusive World Wonder Traced. Oxford: Oxford University Press, 2014. O el de FINKEL, I. L. The hanging gardens of Babylon. In: CLAYTON, Peter. The Seven Wonders of the Ancient World. New York: Routledge, 2008. p. 38-58.

${ }^{8}$ Vide WESTENHOLZ, Aage. The Sumerian city-state. In: HANSEN, M. H. (Ed.). A comparative study of six city-state cultures: an investigation conducted by the Copenhaguen Polis Centre. Copenhague: Kongelige Danske Videnskabernes Selskab, 2002. p. 23-42.

${ }^{9}$ Para un análisis de la cuestión patrimonial perdida puede consultarse el libro de STONE, P. G.; FARCHACK BAJJALY, J. (Ed.). The Destruction of Cultural Heritage in Iraq. New York: Boydell, 2008.

\section{Referencias}

BOTTÉRO, J.; SAMUEL, N. K. (Ed.). Cuando los dioses hacían de hombres: Mitología Mesopotámica. Traducción de Francisco Javier González. Madrid: Akal, 2004.

COOLEY, J. L. Inana and Sukaletuda: a Sumerian Astral Myth. KASKAL: Rivista di storia, ambienti e culture del Vicino Oriente Antico, v. 5, p. 161-172, 2008.

CHAVALAS, M. Women in the Ancient Near East: A Sourcebook. New York: Routledge, 2014.

KRAMER, S. N. History Begins at Sumer. Philadelphia: University of Pennsylvania Press, 1981.

. The Sumerians: Their History, Culture, and Character. Chicago: University of Chicago Press, 1963.

Anos 90, Porto Alegre, v. 25, n. 47, p. 135-147, jul. 2018 
POZZER, Kátia M. P. O jardim do pecado: uma narrativa de violência sexual na Mesopotâmia. In: COSTA GRILLO, J. G. et al (Org.). Sexo e violencia: Realidades antigas e questões contemporâneas. São Paulo: Annablume, 2011. p. 37-58. VOLK, K. Inanna und Šukaletuda: zur historisch-politischen Deutung eines sumerischen Literaturwerkes. Wiesbaden: Harrassowitz, 1995.

WOLKSTEIN, D.; KRAMER, S. N. Inanna: Queen of Heaven and Earth. New York: Harper \& Row, 1983.

Recebido em: 30/12/2017

Aprovado em: 20/02/2018 
